\title{
Pseudo-obstruction and a sprue-like syndrome from strongyloidiasis
}

\author{
C. BARTHOLOMEW* \\ M.D., F.R.C.P.Ed.
}

\author{
A. G. BhaSKAR + \\ M.Sc.
}

\author{
A. K. Butler $\dagger$ \\ M.B., F.R.C.S. \\ N. JANKEY + \\ M.B., M.R.C.Path.
}

\section{Departments of ${ }^{*}$ Medicine, $\uparrow$ Surgery and $\ddagger$ Pathology, General Hospital, Port-of-Spain, Trinidad, West Indies}

\begin{abstract}
Summary
Symptomatic disease from Strongyloides stercoralis has been recognized for the first time in Trinidad. Five cases are reported, all showing clinical features suggestive of a sprue-like syndrome. Subtotal jejunal villous atrophy was seen in one case and partial villous atrophy in two. Three patients had laparotomies because of suspected partial intestinal obstruction. A sprue-like syndrome in certain Caribbean immigrants should arouse a suspicion of $S$. stercoralis.
\end{abstract}

\section{Introduction}

Parasitic infection as a cause of diarrhoea, and malabsorption is well recognized in heavy infections of hookworm (Sheehy et al., 1962) and Giardia lamblia (O'Donovan, McGrath and Boland, 1942). Tissue invasion of the small bowel has been demonstrated in hookworm and giardial infections (Brandborg et al., 1967) but $S$. stercoralis has much more tissue invasive potential.

Infection with Strongyloides stercoralis is protean in its clinical manifestations but a sprue-like pattern is not uncommon.

\section{Case reports}

\section{Case 1}

A 19-year-old male was admitted to the Port-ofSpain General Hospital with a history of diarrhoea and vomiting for 2 months with epigastric pain and distension of the abdomen. He had lost $10 \mathrm{~kg}$ in 5 months.

His haemoglobin was $10.8 \mathrm{~g} / 100 \mathrm{ml}$. White cell count $9000 / \mathrm{mm}^{3}$ with $3 \%$ eosinophils. The serum albumin was $3.1 \mathrm{~g} / 100 \mathrm{ml}$. A barium meal and follow-through showed distension of the coils of the small intestine.

A surgical opinion was sought and a diagnosis of partial intestinal obstruction was made. At operation there was no evidence of mechanical obstruction but there was obvious dilatation of the jejunum. There

Correspondence: Dr C. Bartholomew, General Hospital, Port-of-Spain, Trinidad, West Indies. were also large mesenteric nodes throughout the mesentery. A diagnosis of lymphoma was considered and a biopsy of the jejunum and of a node was taken.

Under the dissecting microscope the jejunal villi appeared convoluted. The patient died on the third postoperative day. The histology of the jejunum showed partial villous atrophy with numerous adult female $S$. stercoralis in the crypts and a moderate infiltrate of round cells and a few eosinophils in the lamina propria. The mesenteric node showed reactive hyperplasia only.

\section{Case 2}

A 46-year-old male was admitted to the Port-of Spain General Hospital with a history of episodic diarrhoea for several months, peri-umbilical pain, anorexia for 6 months with excessive flatulence and borborygmi. There was ankle oedema and weightloss of $15 \mathrm{~kg}$ in 6 months. A barium meal showed delayed gastric emptying. The small bowel coils were dilated and the transit time was increased. A surgical opinion recommended laporatomy but at operation no mechanical obstruction was found. The small bowel was grossly dilated and thickened. The mesenteric nodes were obviously enlarged and a nodal biopsy was reported as showing non-specific adenitis. Two weeks postoperatively his haemoglobin was $9.6 \mathrm{~g} / 100 \mathrm{ml}$; white cell count $9600 / \mathrm{mm}^{3}$ with $6 \%$ eosinophils. The serum albumin was $1.6 \mathrm{~g} / 100$ $\mathrm{ml}$; faecal fat $9 \mathrm{~g} /$ day. An attempt at a small biopsy at this stage was unsuccessful. The patient's diarrhoea worsened and he was put on prednisone 60 $\mathrm{mg}$ a day but died 1 week later. At post-mortem there was some autolysis of the bowel and numerous $S$. stercoralis were present in the mucosa of the small bowel.

\section{Case 3}

A 56-year-old male complained of vomiting, anorexia, epigastric pain, foul-smelling pale loose stools and abdominal distension for 3 months. 


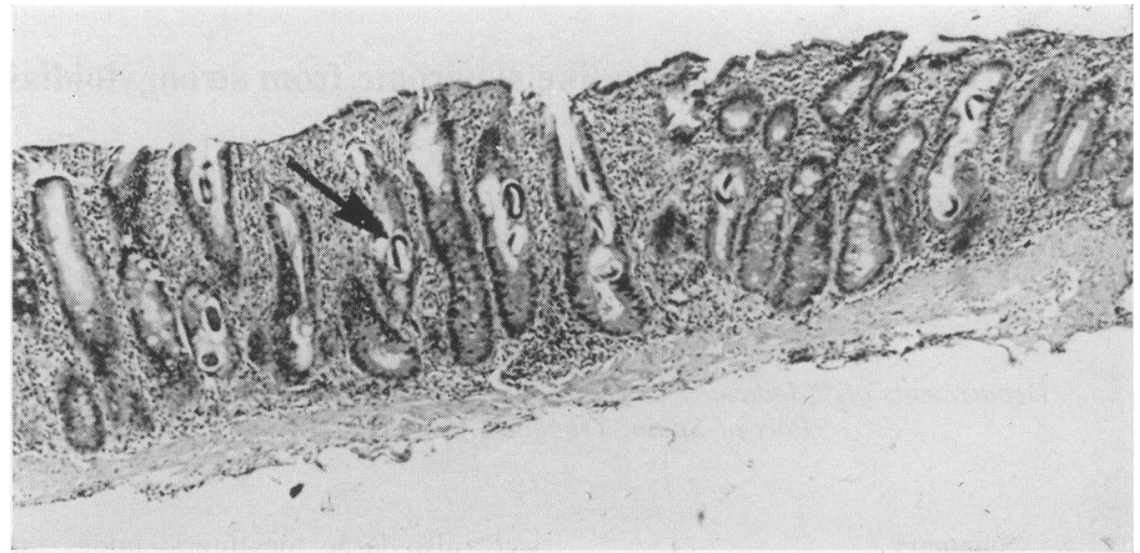

Fig. 1. Low power histology of jejunal mucosa of flat type in case 4 showing helminths in the crypts $(\times 58)$.

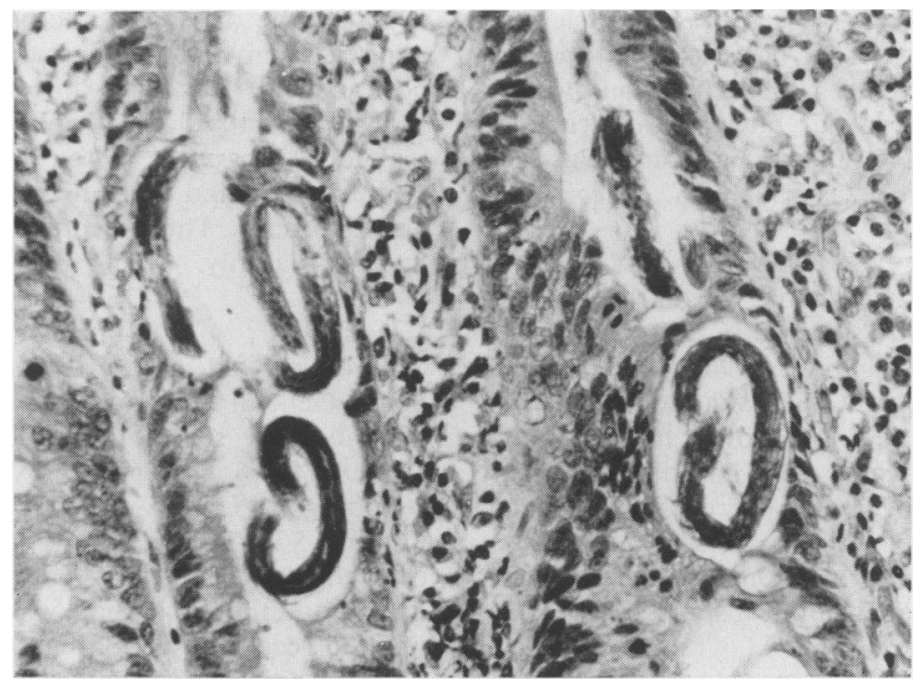

FIG. 2. Higher magnification of jejunal mucosa (case 4) showing helminths curled in crypts $(\times 290)$.

His haemoglobin was $10.3 \mathrm{~g} / 100 \mathrm{ml}$; white cell count $12,200 / \mathrm{mm}^{3}$ with $2 \%$ eosinophils. He was admitted to a surgical unit and a diagnosis of partial small bowel obstruction was made. A barium meal and followthrough showed a distended stomach and dilatation of the small bowel. At $24 \mathrm{hr}$ most of the barium was still in the stomach and small bowel.

A laparotomy was performed. There were grossly dilated and thickened loops of jejunum but there was no evidence of mechanical obstruction. The mesenteric lymph nodes were enlarged. A biopsy of the jejunal mucosa and one of the nodes was taken at operation. The histology of the jejunum showed partial villous atrophy with plasma cells and eosinophilic infiltration in the lamina propria.
Numerous adult female $S$. stercoralis were seen curled up in the crypts of Lieberkühn and ova were present in the stroma.

He was treated with thiabendazole $50 \mathrm{mg} / \mathrm{kg}$ body-weight for 2 days and his symptoms promptlyn subsided. In 2 months he gained $7 \mathrm{~kg}$ and has since regained all his weight. He remains well.

\section{Case 4}

A 50-year-old man was admitted to hospitalo complaining of having semi-solid bowel motionsD four or five times a day for the past 9 months? excessive flatulence, borborygmi, epigastric fullness after meals, oedema and weight-loss of $4 \mathrm{~kg}$ over 3 虰 months. 
His haemoglobin was $11.2 \mathrm{~g} / 100 \mathrm{ml}$; white cell count $6200 / \mathrm{mm}^{3}$ with $9 \%$ eosinophils; serum albumin $3.0 \mathrm{~g} / 100 \mathrm{ml}$; faecal fat $10 \mathrm{~g} /$ day. Stool examination for parasites was negative. A barium meal and follow-through study showed marked dilatation of the jejunum and a slow transit time. A small bowel biopsy showed a flat mucosa under the dissecting microscope and subtotal villous atrophy on histological examination. Lying curled up upon themselves in the crypts were numerous adult $S$. stercoralis and ova. The lamina propria showed round cells and occasional eosinophils (Figs 1 and 2).

$\mathrm{He}$ was treated with thiabendazole $50 \mathrm{mg} / \mathrm{kg}$ body-weight for 2 days and soon recovered. A jejunal biopsy taken 3 weeks later failed to show any Strongyloides and there was a normal villous pattern.

\section{Case 5}

A 41-year-old female was admitted to hospital complaining of weight-loss of $3 \mathrm{~kg}$, intermittent diarrhoea up to twelve times a day, peri-umbilical pain and intermittent vomiting over the past 4 months.

Her haemoglobin was $11.5 \mathrm{~g} / 100 \mathrm{ml}$; white cell count $12,500 / \mathrm{mm}^{3}$ with $5 \%$ eosinophils; serum albumin $3.6 \mathrm{~g} / 100 \mathrm{ml}$; faecal fat $5.0 \mathrm{~g} /$ day. Strongyloides larvae were seen on stool examination. A small bowel biopsy showed a normal villous pattern with a plasma cell and eosinophilic infiltrate in the lamina propria. Adult Strongyloides were seen in the crypts. A barium study was not done.

She was treated with thiabendazole $50 \mathrm{mg} / \mathrm{kg}$ bodyweight and her symptoms subsided soon afterwards. Her weight had increased by $7 \mathrm{~kg}$ in 2 months.

\section{Discussion}

Non-tropical sprue is rare in the West Indies and tropical sprue has been reported only from the islands of Puerto Rico, Haiti and Cuba. Heavy infection with $S$. stercoralis has been reported from Jamaica (Bras et al., 1964), Puerto Rico (Rivera et al., 1970) and now, for the first time, Trinidad. Strongyloidiasis has a tropical preponderance but is fairly cosmopolitan in distribution. Cases have also been reported from Pennsylvania (Ginsberg, 1920), Winnipeg (Cadham, 1933) and Moscow (Shikhobalova and Semenova, 1944).

At times somewhat similar clinical pictures are produced by tropical and non-tropical sprue, and infection with Strongyloides, e.g. flatulence, nausea, vomiting, dyspepsia, abdominal distension and pains, diarrhoea or steatorrhoea, weight-loss and oedema. Like sprue, strongyloidiasis can be quite asymptomatic. However, fatalities occur often enough to merit a wider recognition of this disease particularly in view of the ever-increasing migration of people from tropical countries.
Three of the patients were subjected to surgery with a mistaken diagnosis of partial small bowel obstruction, and at laparotomy there were dilated loops of jejunum without any evidence of mechanical obstruction. The mesenteric nodes were also seen to be enlarged. Even in this respect the similarity to the clinical picture of sprue holds true in that abdominal colic and episodes of pseudo-obstruction may occur in non-tropical sprue (Badenoch, 1960). In a study on non-tropical sprue, Fone et al. (1960) reported that of twelve patients with partial villous atrophy and diarrhoea, five had colicky abdominal pains for which laparotomy was performed in two. In both these patients the small bowel was oedematous and the mesenteric lymph nodes were enlarged Abdominal colic and dilated small intestines have also resulted in erroneous laparotomy for tropical sprue (Baker and Mathan, 1971).

Abdominal lymphadenopathy, as seen in strongyloidiasis, is also seen in non-tropical sprue and as a lymphomatous complication of this disease (Best and Cooke, 1961; Tonkin, 1963), and may lead to erroneous speculations on gross inspection at laparotomy as occurred in Case 1. Moreover, a reticulo-sarcoma, or Hodgkin's disease involvement of the bowel and abdominal nodes, can also cause diarrhoea and steatorrhoea (Sleisenger, Almy and Barr, 1953) and may likewise lead to misdiagnosis initially before histological reports are received.

In strongyloidiasis, the histology of the jejunum may show a normal villous pattern, partial villous atrophy and, as seen in Case 4, strongyloidiasis must now be added to the ever increasing list of diseases resulting in a flat biopsy or subtotal villous atrophy. The nematodes are found curled upon themselves in the crypts of Lieberkühn and some invade the stroma and are seen lying in the interglandular connective tissue and sub-mucosa. The inflammatory response in the interstitial mucosa is characterized by a local eosinophilia and an increased number of plasma cells. Filariform larvae may sometimes also be found in the enlarged mesenteric nodes, and the sinuses may be packed with macrophages, polymorphonuclear neutrophils and a few eosinophils.

Radiological studies in strongyloidiasis have also shown a sprue-like pattern (Patterson, 1958). Rivas-Gomez (1959) in a study of fifty-two cases noted fragmentation of barium especially in the jejunum. The present patients have also shown varying degrees of dilatation of the small bowel and slow transit times, as sometimes seen in both tropical and non-tropical sprue.

Eosinophilia was not marked in the five patients, averaging $5 \%$ and, although several observers have stressed the frequency of eosinophilia, others like Miller et al. (1945) do not believe it to be a constant finding. Faust (1933) believed that there may be an 
early increase in eosinophils with a steady decline as the disease becomes chronic.

Larvae are not always seen in the stool. Repeated stool examinations are advised and if questionable or negative, a study of duodenal aspirations may be rewarding. Strongyloides larvae rapidly disappear from stool specimens kept under refrigeration (Cordi and Otto, 1934) and confusion may also arise in differentiating the larvae of Strongyloides from those of hookworm, especially if the stool specimen has stood long enough to enable hookworm ova to hatch. For this reason fresh stools should be examined.

A sprue-like syndrome in certain Caribbean immigrants should arouse a suspicion of strongyloidiasis. Thiabendazole is an effective therapy.

\section{References}

BADENOCH, J. (1960) Steatorrhoea in the adult. British Medical Journal, 2, 879.

BASER, S.J. \& MATHAN, V.I. (1971) Tropical Sprue and Megaloblastic Anaemia, p. 198. Churchill Livingstone, Edinburgh and London.

Best, C.N. \& Cook, P.B. (1961) Cases of mesenteric reticulosarcoma associated with gluten sensitive steatorrhoea. British Medical Journal, 2, 496.

Brandbord, L.L., TANKersley, C.B., Gottlieb, S., BaranCIK, M. \& SARTOR, V.E. (1967) Histological demonstration of mucosal invasion by Giardia lamblia in man. Gastroenterology, 52, 143.

Bras, G., Richards, R.C., Irvine, R.A., Miner, P.F.A. \& RAGBEeR, M.M.S. (1964) Infection with Strongyloides stercoralis in Jamaica. Lancet, ii, 1257.

CADHam, F.T. (1933) Infestation with Strongyloides ster- coralis associated with severe symptoms. Canadian Medical Association Journal, 29, 18.

Cordi, J.M. \& OTro, G.F. (1934) The effect of various temperatures on the eggs and larvae of Strongyloides. American Journal of Hygiene, 19, 103.

FAUST, E.C. (1933) Experimental studies on human afhd primate species of Strongyloides. II. The development $\overline{\text { gf }}$ Strongyloides in the experimental host. American Journa市 Hygiene, 18 (1), 114.

Fone, D.J., CoOKe, W.T., Meynell, M.J., Brewer, D. HARRIS, E.L. \& Cox, E.V. (1960) Jejunal biopsy in adalt coeliac disease and allied disorders. Lancet, i, 933.

GiNSBERG, L. (1920) Strongyloides intestinalis infestation Journal of the American Medical Association, 75, 1137.

Miller, J.F., EinhoRN, N.H. \& Whittier, L. (1945) Stron gyloides: clinical summary of 11 cases in children. Americ $\overrightarrow{a b}$ Journal of Diseases of Children, 69, 359.

O'Donovan, D.K., McGrath, J. \& Boland, S.J. (1949) Giardial infestation with steatorrhoea. Lancet, ii, 4.

Patterson, D.E. (1958) Strongyloides infestation of jejunum British Journal of Radiology, 31, 102.

Rivas-Gomez, A. (1959) Correspondence. Journal of the American Medical Association, 171, 1135.

Rivera, E., Maldonado, N., Velez-Garcia, E., Grillo A.J. \& Malaret, G. (1970) Hyperinfection syndrome wifl Strongyloides stercoralis. Annals of Internal Medicine, 7 , 199.

Sheehy, T.W., Meroney, W.H., Cox, R.S. \& Soler, J.E (1962) Hookworm dsiease and malabsorption. Gastr疋 enterology, 42, 148.

Shikhobalova, N.P. \& Semenova, N.E. (1944) On the problem of the clinical study and treatment of strongyl. oidosis. Tropical Diseases Bulletin, 41, 411.

Sleisenger, M.H., Almy, T.P. \& BARr, D.P. (1953) sprue syndrome secondary to lymphoma of the small bowel. American Journal of Medicine, 15, 666.

TonkIn, R.D. (1963) Reticulosis of the small bowel as a. Ta complication of idiopathic steatorrhoea. Proceedings of the Royal Society of Medicine, 56, 167. 